\title{
Journal of Infectious Diseases and Diagnosis
}

\section{Adaptability to Various Growth Conditions of Biofilm Associated Extended-Spectrum-Beta-Lactamases Producing Bacteria}

Sinan Baho, Ruth Reid and Shivanthi Samarasinghe

Molecular Microbiology, School of Allied Health Sciences, Faculty of Health and Life Sciences, De Montfort University, the Gateway, LE1 9BH, Leicester, United Kingdom

${ }^{*}$ Corresponding author: Shivanthi Samarasinghe, Molecular Microbiology, School of Allied Health Sciences, Faculty of Health and Life Sciences, De Montfort University, the Gateway, LE1 9BH, Leicester, United Kingdom, Tel: +44(0)116 2078870; E-mail: ssamarasinghe@dmu.ac.uk

Received date: May 8, 2018; Accepted date: May 15, 2018; Published date: May 22, 2018

Copyright: (c) 2018 Baho S, et al. This is an open-access article distributed under the terms of the Creative Commons Attribution License, which permits unrestricted use, distribution, and reproduction in any medium, provided the original author and source are credited.

\begin{abstract}
Extended-Spectrum $\beta$-Lactamase (ESBL) producing bacteria are becoming increasingly prevalent in biofilmassociated infections. Bacteria form biofilms that allow their survival in hostile environments. The amount of formed biofilm is affected by external environmental factors. This study investigates the effect of specific parameters (media type, incubation condition, and growth stage) on the amount of produced biofilm on antibiotic resistant bacterial strains, Escherichia coli (CTX-M-15, TEM-3, and IMP-type) and Klebsiella pneumoniae (OXA-48, SHV-18, NDM-1, and KPC-3). The amount of biofilm formed was measured at different time points $(6,12,24$ and $48 \mathrm{~h}$ ) of incubations under static and shaking conditions, using three different types of media (nutrient broth, LB broth, and AB broth). Statistical tests showed that there was a significant difference in biofilm level $(p<0.01)$ for 64 out of 80 tests $(80 \%)$ when grown under different types of media. Growing under different incubation conditions also showed a statistical difference in biofilm level $(p<0.05)$ for 76 out of 120 tests $(63 \%)$. Stage of growth of the same species also showed statistical difference, 20 out of 24 tests $(83 \%)$ for $E$. coli and 24 out of 24 tests $(100 \%)$ for $K$. pneumoniae. These findings suggested that biofilm formation is highly affected by incubation conditions, strains' stage of growth, and media type demonstrating that these conditions may play a role in adaptability of the ESBLs on different environmental conditions and their increased prevalence in biofilm associated infections.
\end{abstract}

Keywords: ESBLs (Extended spectrum beta lactamases); Biofilms; Antibiotic resistant bacteria; Growth conditions; Third generation antibiotics; Antimicrobial treatments; Carbapenamases; In vitro factors

\section{Introduction}

Over the years, the increase in the incidence of antibiotic resistance in many pathogens has been reported and in many areas worldwide [1]. This increase has been attributed to the changing of microbial characteristics, selective pressure and technological and societal changes that have enhanced the development and spread of antibioticresistant microorganisms. Despite being a natural biological trait, antimicrobial resistance is often enhanced as a result of the adaptation of the infectious agent to exposure to the excessive use of antimicrobials and/or disinfectants in human or agricultural levels [2].

Antibiotic resistance represents one of most significant healthcare problems. The loss of effective antibiotics would weaken the ability to fight infectious diseases and treat the complications for patients with renal dialysis, cancer patients with chemotherapy, and organ transplantation surgery, to whom is the prevention of infections is critical. Healthcare suppliers are obligated to use more toxic doses of antibiotics, more expensive and less effective antibiotics when all options have been exhausted, i.e. first and the second line antibiotic treatment is limited by resistance or is unavailable [3]

In the early 1980s, third-generation cephalosporin played as the forerunner in the fight against $\beta$-lactamase-producing strains. These cephalosporins were developed in response to the increased resistance against $\beta$-lactam antibiotics e.g. ampicillin hydrolyzing $\beta$-lactamases TEM-1 and SHV-1 in Escherichia coli and Klebsiella pneumoniae and their diffusion into new strains like Neisseria gonorrhoeae and
Haemophilus influenzae [4]. In 1983, a plasmid-encoded $\beta$-lactamase able to hydrolyze the extended-spectrum cephalosporins was first reported [5]. Other $\beta$-lactamases closely related to TEM-1 and TEM-2 were soon discovered. Those have the ability to confer resistance to the extended-spectrum cephalosporins [6,7]. These new $\beta$-lactamases were named Extended-Spectrum $\beta$-Lactamases (ESBLs). ESBLs share the ability to hydrolyze third generation cephalosporins and aztreonam, but they are inhibited by clavulanic acid. ESBL are considerably encoded by plasmids. ESBLs include the following types: SHV, TEM, CTX-M, OXA, PER, VEB-1, BES-1 and others [4].

Carbapenems are the best selection for the treatment of different infections caused by ESBL-producing microbes. However, recently it has been reported that many isolates are now carbapenem-resistant. The presence of carbapenems in their molecular structure together with $\beta$-lactam ring gives them this distinction among other $\beta$-lactam antibiotics and confers additional stability against most $\beta$-lactamases including ESBLs [8]. Carbapenem resistance is due to the production of $\beta$-lactamases that can inactivate carbapenems and other $\beta$-lactam antibiotics, therefore, they are called carbapenemases $[9,10]$. These enzymes hydrolyze all or almost all $\beta$-lactams. According to geographical dispersal and carbapenem hydrolysis, the most efficient carbapenemases are IMP, KPC, NDM, VIM, and OXA-48 types [11].

In general, during their growth and proliferation, bacteria can exist in two forms; planktonic, i.e., single, independent cells and, ordered sessile aggregates which are referred to as the biofilm [12]. Physiologically and phenotypically, biofilm-associated cells, which are also called (sessile cells), differ from planktonic or un-attached cells in terms of cell densities, nutrients, and oxygen supply, waste products concentration, and gene expression, and their increased resistance to antimicrobial agents is one of the important characteristics of these 
sessile cells which can reach up to 1000 -fold more than planktonic cells. The latter can be implemented by several mechanisms; resistance genes' exchange within the community e.g. plasmids, transposons, and mobile elements, efflux pumps expression, modifying $\mathrm{pH}$ values and metal ion concentration that leads to inactivation of antibiotic, restriction of antibiotic diffusion through the matrix, efflux pump expression, and the presence of persister cells which are metabolically inactive cells that have high tolerance ability to antibiotics [13-18]. Biofilm formation represents a significant challenge to the healthcare for being the ambiguous reason of why antimicrobial treatments fail, and nearly $65-80 \%$ of all infections are presumably related to biofilm [19-21].

A biofilm can be defined as a microbial community attached irreversibly to a surface (synthetic or biological) and embedded in a matrix composed of extracellular polysaccharide, extracellular DNA (eDNA) and proteins [22,23].

Biofilm formation (Figure 1) is implemented in five steps in the diagram $[22,24]$.

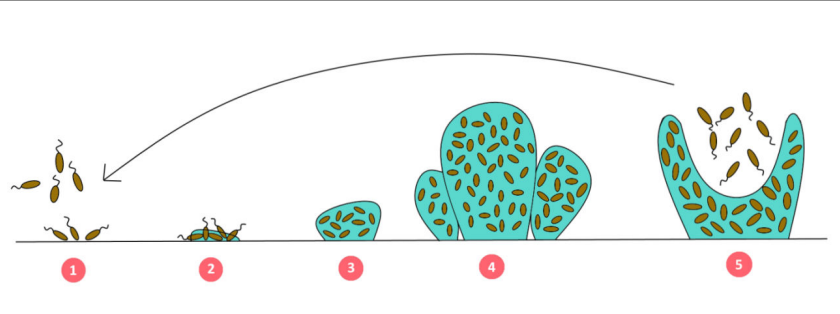

Figure 1: Graphic illustrating the biofilm formation process; 1) reversible attachment to a surface. 2) Irreversible attachment, the formation of exopolysaccharides. 3) Initiation of biofilm maturation through the formation of biomolecules complex layer and exopolysaccharides secretion. 4) Three-dimensional structure biofilm containing clusters of macrocolonies interspersed by channels for nutrients and wastes transfer. 5) Detachment and spread of biofilm cells after maturation.

Planktonic bacterial infections are usually treatable with normal antibiotics; this is termed as acute infection. On the other hand, the untreatable one which involves biofilm formation is termed as chronic infection, in which bacteria usually have maximum resistance to antibiotics [12]. Biofilm complexity is aggravated by the fact that they are genetically heterogeneous [25]. Biofilm can be stratified (in natural biofilm community) due to the migration of its resident microorganisms towards the optimal conditions for gaining light, nutrients, secondary metabolites, oxygen and signaling compounds [26-28].

Three factors redound to the heterogeneity of the biofilm; (i) physiological heterogeneity, to which bacteria adapt to their regional environmental conditions e.g. nutrients and oxygen diffusion from their sources into the biofilm and then utilized by the bacteria. This leads to the development of a chemical concentration gradient that overlaps with the waste products and signaling compounds gradients forming many unique microenvironments in the same biofilm structure which, in turn, leads bacteria to respond to those conditions and thus individual cells physiology may differ from nearby cells [29-31]. (ii) Genetic variability, in which mutation might happen in a clonal population of cells. This might lead to cellular differentiation
$[32,33]$. (iii) Stochastic gene expression, where the same genes are expressed at different levels among subsets of cells even if those cells in the same environmental conditions. This leads to the development of a subpopulation of cells within the same community that differs from the original mother cells [34-37].

This study analyses the effect of selected in vitro factors, such as static and shaking incubation conditions, the different growth media, and the duration of the incubation on the amount of biofilm production by clinically important antibiotic resistant bacterial strains.

\section{Materials and Methods}

\section{Bacterial strains}

Antibiotic-resistant carbapenemases $E$. coli (IMP-type), $K$. pneumoniae (KPC-3, NDM-1, and OXA-48) and ESBL E. coli (CTXM-15, TEM-3) and $K$. pneumoniae (SHV-18) were used in this study. In addition, two standard antibiotic sensitive strains $E$. coli (NCTC 12241) and K. pneumoniae (NCTC 9633) were used to compare the amount of their biofilm with the antibiotic-resistant ones. E. coli NCTC 10538 (K12) was used as a standard stain for biofilm production. All strains were obtained from National Collection of Type Cultures (NCTC) and were grown on nutrient agar plates and incubated overnight at $37^{\circ} \mathrm{C}$. Before performing the assay, a loopful of bacterial colonies was inoculated into $5 \mathrm{ml}$ of LB and N.B and incubated for $18 \mathrm{~h}$ at $37^{\circ} \mathrm{C}$ in static incubator for static growth and in shaking at $70 \mathrm{rpm}$ for shaking growth.

\section{Antibiotic sensitivity testing using double disk diffusion testing}

Double disk diffusion testing was performed according to the manufacturer instructions [8], two sets were used which are D67C and D70C.

BSAC methods for antimicrobial susceptibility testing were utilized for the preparation of the inoculums to give a semi-confluent growth of colonies after overnight incubation [39], a comparison between these inoculums and $0.5 \mathrm{McF}$ arland standard was made.

$0.5 \mathrm{McFarland}$ standard was prepared by adding $0.5 \mathrm{ml}$ of $0.048 \mathrm{M}$ $\mathrm{BaCl}_{2}$ to $99.5 \mathrm{ml}$ of $0.18 \mathrm{M} \mathrm{H}_{2} \mathrm{SO}_{4}$ with constant stirring. Absorbance was measured at a wavelength of $625 \mathrm{~nm}$. Absorbance range was adjusted to fall within $(0.08-0.13)$. Standards were distributed into screw-cap tubes of the same size and volume as for the ones used for broth cultures and stored at room temperature and protected from light.

After incubation, test strains grown on nutrient broth were streaked onto Mueller-Hinton Agar (MHA) and incubated with the related disks sets at $37^{\circ} \mathrm{C}$ for $18-20 \mathrm{~h}$. Positive ESBL were defined as a zone of diameter difference of $\geq 5 \mathrm{~mm}$ when D67C disks were used. While for D70C, a zone of diameter difference of $\geq 4 \mathrm{~mm}$ with disk $\mathrm{C}$ and $\geq 5$ $\mathrm{mm}$ with disk $\mathrm{B}$ compared with disk $\mathrm{A}$.

\section{Molecular detection of the presence of antibiotic resistance gene sequence using the PCR}

Polymerase chain reaction was done by using a thermal cycler [40]. A suitable set of primers were designed that target resistance gene in the specific strain. Three fresh colonies were picked up from each overnight grown strain on agar medium. These colonies were 
inoculated into $50 \mu \mathrm{l}$ of sterilized distilled water in an Eppendorf tube, heated at $94^{\circ} \mathrm{C}$ for $10 \mathrm{~min}$ in a heat block, centrifuged for $1 \mathrm{~min}$ at $14000 \mathrm{rpm}$ and $1 \mu \mathrm{l}$ of the supernatant was used as a template for the PCR reaction. The following reaction mixture was added to each sample: $1 \mu \mathrm{l}$ bacterial DNA, $10 \mu \mathrm{l}$ X Green GoTaq Flexi Buffer, $5 \mu \mathrm{l}$ $\mathrm{MgCl}_{2}, 1 \mu \mathrm{dNTP}, 0.5 \mu \mathrm{l}$ upstream primer, $0.5 \mu \mathrm{l}$ downstream primer, $0.25 \mu \mathrm{l} \mathrm{GoTaq}$ Flexi DNA polymerase and completed to $50 \mu \mathrm{l}$ volume $\mathrm{H}_{2} \mathrm{O}$. To confirm the positive results are not from contamination, negative controls were prepared by replacing $1 \mu$ of $\mathrm{H}_{2} \mathrm{O}$ instead of bacterial DNA and for each set of the selected primers. Each set of primers gave a PCR product of the sizes in base pairs mentioned in Table 1.

\begin{tabular}{|l|l|l|l|}
\hline Primer & Sequence (5'-3') & Target & $\begin{array}{l}\text { Amplicon } \\
\text { size (bp) }\end{array}$ \\
\hline OXA-48F & CGGAATGCCTGCGGTAGCA & blaOXA-48 & 713 \\
\hline OXA-48R & TGATGGCTTGGCGCAGC & & \\
\hline KPC-3F & GCGGAACCATTCGCTAAAC & blaKPC-3 & 864 \\
\hline KPC-3R & GACAGTGGTTGGTAATCCATGC & & \\
\hline NDM-1F & AATGGAACTGGCGACCAAC & blaNDM-1 & 322 \\
\hline NDM-1R & TCGACAACGCATTGGCATAA & & \\
\hline IMP-6F & GCAGCATTGCTACCGCAG & blaIMP-type & 657 \\
\hline IMP-6R & CCGCCTGCTCTAATGTAAGT & & \\
\hline CTX-M1-F & AAAAATCACTGCGCCAGTTC & blaCTX-M-15 & 370 \\
\hline CTX-M1-R & AGCTTATTCATCGCCACGTT & & \\
\hline SHV-18F & $\begin{array}{l}\text { CTCAAGGATGTATTGTGGTTAT } \\
\text { GC blaSHV-18 }\end{array}$ & 912 \\
\hline SHV-18R & CGAGCCGGATAACGCGCGCG & & \\
\hline TEM-1F & GTAAAAGATCCTGAAGATCAG & blaTEM-3 & 768 \\
\hline TEM-1R & CCAATGCTTAATCAGTGAGG & & \\
\hline
\end{tabular}

Table 1: List of primers that were used in this study.

\section{Biofilm formation assay (Tissue culture plate assay; TCP)}

Tissue culture plate assay was used to determine the biofilm formation and according to the procedure mentioned in Beehan et al., Lee et al., and Fattahi et al. [41-43] with modifications as follows: overnight incubated cultures were diluted to an $\mathrm{OD}_{260}$ of 0.01 in $5 \mathrm{ml}$ of N.B, LB and AB medium in the six wells TCP (colonies that were grown in LB were inoculated into TCP that contains $\mathrm{LB}$ and $\mathrm{AB}$, while colonies that were grown in N.B were inoculated into the TCP that contains N.B) and each strain was cultured in triplicate. All inoculated TCPs were incubated at $37^{\circ} \mathrm{C}$ in a static incubator (for static cultures) and a shaker incubator at $70 \mathrm{rpm}$ (for the cultures previously incubated in shaker incubator) and at different incubation periods (time points); 6, 12, 24 and $48 \mathrm{~h}$ to see at which time point the biofilm form higher [44]. After incubation, the broth was carefully drawn using a Pasteur pipette and the wells were washed three times using a sterile Phosphate Buffer Saline (PBS). Bacteria in the wells were fixed by adding $5 \mathrm{ml}$ of $99 \%$ methanol for $15 \mathrm{~min}$, then discarded and left to dry in an inverted position for $30 \mathrm{~min}$ at room temperature. Each well was stained with $5 \mathrm{ml}$ of $2 \%$ crystal violet for $5 \mathrm{~min}$ at room temperature; Excess stain was rinsed with sterilised distilled water. The remaining dye was re-solubilised with $4 \mathrm{ml}$ of $33 \%$ glacial acetic acid and let at room temperature for $30 \mathrm{~min}$. Finally, optical density for each well was measured at $570 \mathrm{~nm}$ using Helios Gamma UV-Vis spectrophotometer.

\section{Statistics}

A one-way ANOVA and a t-test were used to test the significant difference in biofilm formation amount. For one-way ANOVA, a pvalue of $<0.01$ was considered significant when comparing biofilm amount in different mediums. For the t-test, a p-value of $<0.05$ was considered significant when comparing biofilm amount between static and shaking incubation conditions. A descriptive study was performed by classifying all isolates into the following categories according to their highest $\mathrm{OD}_{260}$ values among the four growth stages for the specific strain: $\mathrm{OD}_{260}$ value $=0$ (no adherent), $\mathrm{OD}_{260}$ value $<0.2$ (weakly adherent), $\mathrm{OD}_{260}$ value $0.2-0.4$ (moderately adherent), and $\mathrm{OD}_{260}$ value $>0.4$ (strongly adherent). Mean, standard error, and $95 \%$ confidence interval were calculated for the above mentioned optical densities to examine the rate of adherence among the selected tests in different media under different incubation conditions in total. Oneway ANOVA also was used with a p-value of $<0.005$ to test the significant difference in biofilm formation ability for each species' strains at the same growth stage in different media and under both static and shaking incubation. i.e. K. pneumoniae strains and $E$. coli strains.

\section{Results}

The purpose of this study was to analyse the effect of growth media, the effect of static or shaking conditions, and the time point of biofilm formation. Six well tissue culture plates were used to inoculate $5 \mathrm{ml}$ of nutrient broth and LB broth of the bacterial inoculum for periods of 6 , 12,24 and $48 \mathrm{~h}$ incubation at static and shaking conditions and to measure the amount of biofilm formed by each strain. Crystal violet was used to stain the biofilm to be measured by a spectrophotometer at a wavelength of $570 \mathrm{~nm}$ after dissolving it in $33 \%$ glacial acetic acid. Figures 2 and 3 show the results for the biofilm formed by the test strains.

The presence of ESBL or carbapenemases was determined by comparing the zone size of antibiotics discs with their simultaneously incubated antibiotics plus inhibitor combinations (Figure 2). Zone of inhibition size was measured in millimeter units, recorded on a table and interpreted using MAST standard instructions and as shown in Tables 2 and 3.

\section{D67C ESBL Set}

\begin{tabular}{|l|l|l|l|l|l|l|l|}
\hline Strain & CPD & CPD CV & CTX & CTX CV & CAZ & CAZ CV & Interpretation \\
\hline K. pneumoniae OXA-48 & 18 & 18 & 21 & 21 & 22 & 22 & Non-ESBL \\
\hline
\end{tabular}


Citation: Baho S, Reid R, Samarasinghe S (2018) Adaptability to Various Growth Conditions of Biofilm Associated Extended-Spectrum-BetaLactamases Producing Bacteria. J Infect Dis Diagn 3: 121. doi:10.4172/2576-389X.1000121

Page 4 of 9

\begin{tabular}{|l|l|l|l|l|l|l|l|}
\hline K. pneumoniae SHV-18 & 8.5 & 19 & 15 & 20 & 9 & 21 & ESBL \\
\hline K. pneumoniae NDM-1 & 7 & 7 & 7 & 7 & 7 & 7 & Non-ESBL \\
\hline K. pneumoniae KPC-3 & 6 & 6 & 9 & 10 & 6 & 6 & Non-ESBL \\
\hline K. pneumoniae 9633 & 25 & 25 & 29 & 29 & 23 & 22 & Non-ESBL \\
\hline E. coli IMP-type & 6 & 6 & 7.5 & 7.5 & 6 & 6 & Non-ESBL \\
\hline E. coli CTX-M-15 & 6 & 17 & 6 & 15 & 11 & 24 & ESBL \\
\hline E. coli TEM-3 & 6 & 21 & 13 & 23 & 10 & 26.5 & ESBL \\
\hline E. coli 12241 & 22.5 & 23 & 29 & 30 & 27 & 27 & Non-ESBL \\
\hline
\end{tabular}

Table 2: D67C ESBL set for confirmation of ESBL production in Enterobacteriaceae with no chromosomal de-repressed or inducible AmpC. As shown below, K. pneumoniae SHV-18, E. coli CTX-M-15 and E. coli TEM-3 showed a zone difference between the antibiotic and its inhibitor, so they are ESBL.
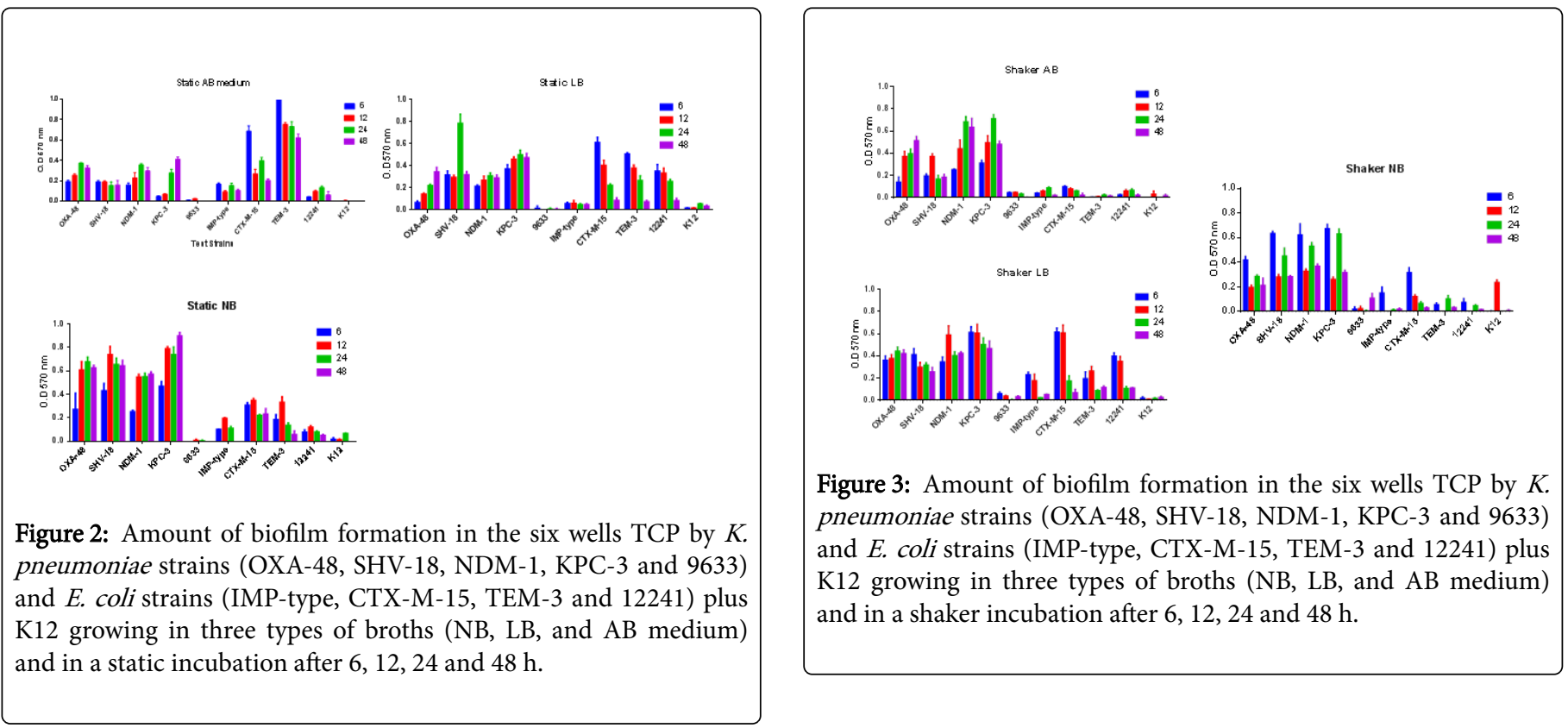

\begin{tabular}{|l|l|l|l|l|l|}
\hline \multicolumn{7}{|l|}{ D70C carbapenemase } & D70A & D70B & D70C & D70D & Interpretation \\
\hline Strain & 19 & 18 & 18 & 19 & Molecular testing required \\
\hline K. pneumoniae OXA-48 & 27 & 26 & 26 & 27 & -ve \\
\hline K. pneumoniae SHV-18 & 7 & 14 & 7 & 7 & MBL activity \\
\hline K. pneumoniae NDM-1 & 6 & 8 & 13 & 9 & KPC3 activity \\
\hline K. pneumoniae KPC-3 & 29 & 27 & 27 & 28 & -ve \\
\hline K. pneumoniae 9633 & 13 & 22 & 15 & 16 & MBL activity \\
\hline E. coli IMP-type & 27 & 26 & 27 & 27 & -ve \\
\hline E. coli CTX-M-15 & 31 & 29 & 30 & 31 & -ve \\
\hline E. coli TEM-3 & & & & & \\
\hline
\end{tabular}


Citation: Baho S, Reid R, Samarasinghe S (2018) Adaptability to Various Growth Conditions of Biofilm Associated Extended-Spectrum-BetaLactamases Producing Bacteria. J Infect Dis Diagn 3: 121. doi:10.4172/2576-389X.1000121

Page 5 of 9

\begin{tabular}{|l|l|l|l|l|l|}
\hline E. coli 12241 & 28 & 28 & 27 & 28 & - ve \\
\hline
\end{tabular}

Table 3: D70C carbapenemases detection disk set for the detection of carbapenemase enzyme production in Enterobacteriaceae. This test detects carbapenemases with only MBL and KPC types. $K$. pneumoniae NDM-1 and E. coli IMP-type showed MBL activity; K. pneumoniae KPC-3 showed KPC-3 activity while $K$. pneumoniae OXA-48 did not show any carbapenemase activity. Therefore, additional testing for confirmation was required.

The molecular detection test was done to confirm the presence of the resistance genes within our bacterial test strains' genome. Specific primers were designed for this purpose that would bind to the resistance sequence to give a DNA fragment product with specified length. By visualizing the bands on the gel, their sizes could be inferred in comparison with the aligned ladders. Figure 4 shows the results of the gel electrophoresis for the test strains. After obtaining these results, a comparison has been made with the expected fragments' sizes, and they were nearly the same as expected. Therefore, all our test strains were harboring the antibiotic resistance gene related to their strains.

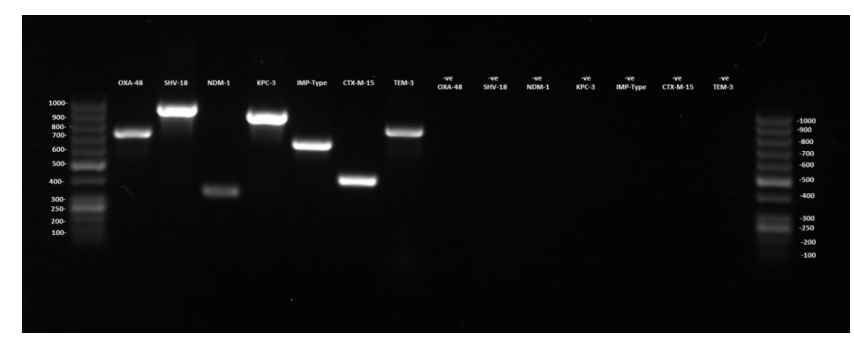

Figure 4: Gel electrophoresis for the PCR products of the seven antibiotic resistance genes' primers. By looking at the gel, it can easily deduct the size of the fragments. The first line from left shows a band of a DNA fragment of $713 \mathrm{bp}$ which was exactly as expected for an OXA-48 fragment, then 912 bp for SHV-18, 322 bp for NDM-1, 864 bp for KPC-3, 657 bp for IMP-type, 370 bp for CTXM-15 and 768 bp for TEM-3. Negative control for each sets of the selected primers showed that there were no bands. $1 \%$ agarose in $1 \mathrm{X} \mathrm{TAE}, 5 \mathrm{~V} / \mathrm{cm}$.

Tested isolates have been classified according to their $\mathrm{OD}_{260}$. The classification system used in this study was based on previous study done by Beehan et al. [41]. As shown on Table 4 , an $\mathrm{OD}_{260}$ above 0.2 in any test was considered as indication to show adherence required for biofilm formation. For the total tests (all media types and incubation conditions), $40 \%(24 / 60)$ showed weakly adherence, 23\% (14/60) showed moderate adherence, while the rest $37 \%(22 / 60)$ showed a strong adherence. The mean $\mathrm{OD}_{260} \pm$ standard error of the strongly adherent test was $0.63 \pm 0.03$, with $33 \%$ for the static incubation and $40 \%$ for the shaking incubation.

\begin{tabular}{|l|l|l|l|l|l|l|}
\hline OD value & Non-adherent & $\begin{array}{l}\text { No. of } \\
\text { tests }\end{array}$ & Mean O.D & SE & $\mathbf{9 5 \%}$ Cl & $\%$ \\
\hline$<0.2$ & $\begin{array}{l}\text { Weakly } \\
\text { adherent }\end{array}$ & $24 / 60$ & 0.08 & 0.01 & 0.02 & $40 \%$ \\
\hline $0.2-0.4$ & $\begin{array}{l}\text { Moderately } \\
\text { adherent }\end{array}$ & $14 / 60$ & 0.33 & 0.01 & 0.03 & $23 \%$ \\
\hline$>0.4$ & $\begin{array}{l}\text { Strongly } \\
\text { adherent }\end{array}$ & $22 / 60$ & 0.63 & 0.03 & 0.07 & $37 \%$ \\
\hline
\end{tabular}

Table 4: Biofilm classification results for the isolates according to their specified test.

The TCP assay showed that there was a significant difference $(p<0.01)$ in biofilm formation ability among the bacterial strains grown in different growth mediums for all of the tested strains and for both incubation conditions; static and shaking when at the same growth stage, except for (K12, 9633, CTX-M-15, and SHV-18 at 6hr), (CTXM-15 at $12 \mathrm{~h}),(\mathrm{K} 12$ and 9633 at $24 \mathrm{~h})$ and (12241 and 9633 at $48 \mathrm{~h})$ under the static conditions, and (9633 and K12 at 6 h), (SHV-18 and 9633 at $12 \mathrm{~h}$ ), and (SHV-18, K12 and CTX-M-15 at $48 \mathrm{~h}$ ) under the shaking conditions. $60 \%$ showed significant difference at $6 \mathrm{~h}$ growth, $90 \%$ at $12 \mathrm{~h}$, and $80 \%$ for both 24 and $48 \mathrm{~h}$ of growth during static incubation. While $80 \%$ for both 6 and $12 \mathrm{~h}, 100 \%$ at $24 \mathrm{~h}$, and $70 \%$ at $48 \mathrm{~h}$ of growth during shaking incubation.

There was a statistical difference $(\mathrm{p}<0.05)$ in biofilm formation ability within the same strain grown in the same medium but in different incubation conditions (static and shaking) and for some of the tested strains. $70 \%$ on $\mathrm{AB}$ broth, $55 \%$ on LB broth, and $65 \%$ on N.B (Table 5).

\begin{tabular}{|c|c|c|c|c|c|c|c|c|c|c|c|c|}
\hline \multirow[t]{2}{*}{ Strains } & \multicolumn{4}{|l|}{ AB } & \multicolumn{4}{|l|}{ LB } & \multicolumn{4}{|l|}{ N.B } \\
\hline & $6 \mathrm{~h}$ & $12 \mathrm{~h}$ & $24 \mathrm{~h}$ & $48 \mathrm{~h}$ & $6 \mathrm{~h}$ & $12 \mathrm{~h}$ & $24 \mathrm{~h}$ & $48 \mathrm{~h}$ & $6 \mathrm{~h}$ & $12 \mathrm{~h}$ & $24 \mathrm{~h}$ & $48 \mathrm{~h}$ \\
\hline K. pneumoniae OXA-48 & N & $\mathrm{Y}$ & $\mathrm{N}$ & $\mathrm{Y}$ & $\mathrm{N}$ & Y & Y & $\mathrm{N}$ & $\mathrm{N}$ & Y & Y & Y \\
\hline K. pneumoniae SHV-18 & $\mathrm{N}$ & $\mathrm{Y}$ & $\mathrm{N}$ & $\mathrm{N}$ & $\mathrm{Y}$ & $\mathrm{N}$ & $\mathrm{N}$ & $\mathrm{N}$ & $\mathrm{N}$ & $\mathrm{Y}$ & $\mathrm{Y}$ & $\mathrm{Y}$ \\
\hline K. pneumoniae NDM-1 & $\mathrm{Y}$ & $\mathrm{Y}$ & $\mathrm{Y}$ & $\mathrm{Y}$ & $\mathrm{Y}$ & $\mathrm{Y}$ & $\mathrm{Y}$ & $\mathrm{Y}$ & $\mathrm{Y}$ & $\mathrm{Y}$ & $\mathrm{N}$ & $\mathrm{Y}$ \\
\hline K. pneumoniae KPC-3 & Y & $\mathrm{Y}$ & $\mathrm{Y}$ & $\mathrm{N}$ & $\mathrm{Y}$ & $\mathrm{Y}$ & $\mathrm{N}$ & $\mathrm{N}$ & $\mathrm{Y}$ & $\mathrm{Y}$ & $\mathrm{N}$ & Y \\
\hline K. pneumoniae 9633 & $\mathrm{Y}$ & $\mathrm{Y}$ & $\mathrm{Y}$ & $\mathrm{N}$ & N & Y & N & Y & $\mathrm{N}$ & Y & $\mathrm{N}$ & Y \\
\hline E. coli IMP-type & $\mathrm{Y}$ & $\mathrm{Y}$ & $\mathrm{Y}$ & $\mathrm{Y}$ & $\mathrm{Y}$ & $\mathrm{Y}$ & $\mathrm{Y}$ & $\mathrm{Y}$ & $\mathrm{N}$ & $\mathrm{Y}$ & $\mathrm{Y}$ & $\mathrm{Y}$ \\
\hline
\end{tabular}




\begin{tabular}{|l|l|l|l|l|l|l|l|l|l|l|l|l|l|}
\hline E. coli CTX-M15 & Y & Y & Y & Y & N & Y & N & N & N & Y & Y & Y \\
\hline E. coli TEM-3 & Y & Y & Y & Y & Y & Y & Y & Y & Y & Y & N & N \\
\hline E. coli 12241 & Y & Y & Y & N & N & N & Y & N & N & N & Y & Y \\
\hline E. coli K12 & N & N & N & N & N & Y & N & N & N & Y & Y & N \\
\hline
\end{tabular}

Table 5: $t$-test results showing the presence of the statistical difference among the tested strains regarding the difference in biofilm formation amount in different incubation conditions (static and shaking). Y: Yes; N: No. $(\mathrm{p}<0.05)$.

In a previous study done by Beehan et al. [41], E. coli k12 was used as a positive control for the biofilm formation, therefore we chose to use it in our study. In this study, it showed a very weak biofilm produced in general. However, what was noticeable and interesting is that it showed a sudden jump in biofilm amount when grown in N.B after $12 \mathrm{hrs}$ in shaking incubation conditions and in LB after $24 \mathrm{~h}$ in static incubation conditions. The amount of biofilm formation was compared with two non-antibiotic resistant strains (E. coli 12241 and K. pneumoniae 9633).

Table 6 shows the difference in biofilm formation amount at the same growth stage in different media and incubation conditions. Each strain showed its maximum biofilm amount in different media upon different growth stages and under different conditions of incubation. Table 7 summarizes the results.

\begin{tabular}{|l|l|l|l|l|l|l|l|l|}
\hline \multicolumn{4}{|l}{} & \multicolumn{9}{l|}{ Static } \\
\hline AB & $\mathbf{6}$ & $\mathbf{1 2}$ & $\mathbf{2 4}$ & $\mathbf{4 8}$ & $\mathbf{6}$ & $\mathbf{1 2}$ & $\mathbf{2 4}$ & $\mathbf{4 8}$ \\
\hline K. pneumoniae & $\mathrm{Y}$ & $\mathrm{Y}$ & $\mathrm{Y}$ & $\mathrm{Y}$ & $\mathrm{Y}$ & $\mathrm{Y}$ & $\mathrm{Y}$ & $\mathrm{Y}$ \\
\hline E. coli & $\mathrm{Y}$ & $\mathrm{Y}$ & $\mathrm{Y}$ & $\mathrm{Y}$ & $\mathrm{Y}$ & $\mathrm{Y}$ & $\mathrm{Y}$ & $\mathrm{N}$ \\
\hline LB & 6 & 12 & 24 & 48 & 6 & 12 & 24 & 48 \\
\hline K. pneumoniae & $\mathrm{Y}$ & $\mathrm{Y}$ & $\mathrm{Y}$ & $\mathrm{Y}$ & $\mathrm{Y}$ & $\mathrm{Y}$ & $\mathrm{Y}$ & $\mathrm{Y}$ \\
\hline E. coli & $\mathrm{Y}$ & $\mathrm{Y}$ & $\mathrm{N}$ & $\mathrm{N}$ & $\mathrm{Y}$ & $\mathrm{Y}$ & $\mathrm{Y}$ & $\mathrm{Y}$ \\
\hline NB & 6 & 12 & 24 & 48 & 6 & 12 & 24 & 48 \\
\hline K. pneumoniae & $\mathrm{Y}$ & $\mathrm{Y}$ & $\mathrm{Y}$ & $\mathrm{Y}$ & $\mathrm{Y}$ & $\mathrm{Y}$ & $\mathrm{Y}$ & $\mathrm{Y}$ \\
\hline E. coli & $\mathrm{Y}$ & $\mathrm{Y}$ & $\mathrm{Y}$ & $\mathrm{Y}$ & $\mathrm{Y}$ & $\mathrm{Y}$ & $\mathrm{Y}$ & $\mathrm{N}$ \\
\hline
\end{tabular}

Table 6: One-way ANOVA test showing the presence of the statistical difference among the tested strains regarding the difference in biofilm formation amount at the same growth stage in different media and incubation conditions (static and shaking). Y: Yes, N: No. $(\mathrm{p}<0.005)$.

\begin{tabular}{|l|l|l|l|}
\hline Strains & Growth stage & $\begin{array}{l}\text { Incubation } \\
\text { conditions }\end{array}$ & Medium \\
\hline $\begin{array}{l}\text { K. pneumoniae } \\
\text { OXA-48 }\end{array}$ & $24 \mathrm{~h}$ & Static & N.B \\
\hline $\begin{array}{l}\text { K. pneumoniae } \\
\text { SHV-18 }\end{array}$ & $24 \mathrm{~h}$ & Static & AB \\
\hline K. pneumoniae NDM-1 & $24 \mathrm{~h}$ & Shaker & AB \\
\hline K. pneumoniae KPC-3 & $48 \mathrm{~h}$ & Static & N.B \\
\hline K. pneumoniae 9633 & $48 \mathrm{~h}$ & Shaker & N.B \\
\hline
\end{tabular}

\begin{tabular}{|l|l|l|l|}
\hline E. coli IMP-type & $6 \mathrm{~h}$ & Shaker & LB \\
\hline E. coli CTX-M15 & $\begin{array}{l}6 \mathrm{~h} \text { in static/6and 12 } \mathrm{h} \text { in } \\
\text { shaker }\end{array}$ & $\begin{array}{l}\text { Static/ } \\
\text { Shaker }\end{array}$ & LB \\
\hline E. coli TEM-3 & $6 \mathrm{~h}$ & Static & AB \\
\hline E. coli 12241 & $6 \mathrm{~h}$ & Shaker & LB \\
\hline E. coli K12 & $12 \mathrm{~h}$ & Shaker & N.B \\
\hline
\end{tabular}

Table 7: Maximum amount of produced biofilm for each strain at which growth stage, incubation conditions, and growth medium.

\section{Discussion}

In general, the biofilm formation process is poorly understood [45], and there are limited studies comparing the amount of biofilm production in $E$. coli and $K$. pneumoniae between different media types, incubation under static and shaking conditions, and measuring the amount at different growth stages. In this study, we emphasized our understanding of measuring biofilm by using antibiotic-resistant strains and we tried to find out how biofilm amount could be affected by different growth parameters, will those parameters be agreed with all the tested strains, and which strain among those selected antibioticresistant can give the highest amount of biofilm and under which conditions. From the obtained results it could be noticed clearly that there are distinctive variations in the amount of biofilm formation among our selected antibiotic-resistant $E$. coli and $K$. pneumoniae strains growing in different types of media, incubated at four different stages, different incubation conditions (static and shaking).

In this study, we tried to find out the optimal conditions under which each selected single strain will produce the highest amount of biofilm. In other words, which strain has the highest amount of biofilm, under which incubation condition, which medium and on which stage of growth. According to the results, there were no media preferences can be agreed to all the strains during biofilm production, nor with their specific stage of growth. In fact, there were remarkable variations among tested strains amplitude to form biofilm in vitro. However, one can say that an individual strain produces a better amount of biofilm on some media compared to others in specified stages of growth. This might be due to the nutrient content of the medium, this was shown by Stepanović et al. [46]. This, in turn, is governed by the genetic factors that have a dramatic role in biofilm formation, related to media composition [47]. Static and shaking incubation were used in our research to study the effect of aeration and nutrient distribution on biofilm development and amount.

Our study showed that $37 \%(22 / 60)$ of all tests demonstrated strong biofilm formation, mainly in LB and NB. This might be an indication 
that those media are the preferred ones for those strains to produce their highest amount of biofilm.

In our study we used the crystal violet assay to evaluate biofilm formation amount. This assay evaluates the early stages of biofilm formation, exopolysaccharides production, and bacterial attachment. It is a basic dye that attach to any remaining exopolysaccharides and bacteria that stay after well washing. This assay is seen as the gold standard for biofilm evaluation for a wide range of bacteria and even fungi [48]. It is an inexpensive static test with a flexible protocol that allows a high throughput of isolates [49].

Biofilm was measured at four growth stages $(6,12,24$, and $48 \mathrm{~h})$ of incubation, as within those stages there are different biofilm developmental events could happen including attachment, exopolysaccharides secretion, three-dimensional structure formation (maturation), and detachment [50,51]. As we proposed that those selected time-stages would not be the same for all strains regarding biofilm development as each strain differs from another phenotypically and genotypically, our results confirmed this in that $100 \%$ of $K$. pneumoniae strains and $83 \%$ of $E$. coli strains showed a significant difference at the selected growth stages and for both static and shaking incubation.

In his study, Reisner et al. [47] reported that different $E$. coli isolates respond differently to variations in environmental conditions regarding the amount of biofilm formation. He also stated that "biofilm formation of a given test strain in one medium does not enable prediction of biofilm formation of the same strain in a different medium". He also found that the increase in biofilm formation in nondomesticated $E$. coli isolates in vitro is not sufficient to be attributed to specific factors (curli, F-like conjugative pili and aggregative adherence fimbriae) that are well known to stimulate biofilm formation. This might explain the sudden increase in biofilm amount in E. coli $\mathrm{k} 12$. Researchers found that there was a weak correlation between biofilm formations in different media. This in turn will increase the difficulty to mimic the in vivo environment by means of finding the proper conditions for in vitro biofilm formation $[47,52]$.

Two other strains that were non-antibiotic resistant strains ( $E$. coli 12241 and K. pneumoniae 9633) have been used as standard strains to compare their amount of biofilm formation with their other same species with antibiotic resistance. The amount of biofilm produced by $K$. pneumoniae when grown in NB was higher than that in LB in the static incubation. Likewise, our results matched with those obtained by Reisner et al.s [47] study.

One can see from the graph that biofilm production amount was higher in antibiotic-resistant strains than that in the non-antibiotic resistant strains. This result agreed with the one done by Corehtash et al. [53] who found that multidrug-resistant $P$. aeruginosa isolates form higher biofilm than in the non-multidrug-resistant isolates. $\mathrm{He}$ explained that this might be due to the delayed penetration of antimicrobial agents inside the bacterial cell.

One of limitations of this study was the small sample size which can affect the statistical results. However, many tests has been made for the same strain and taken into considerations to emphasize the propability of our calculations. Another limitation was the lack of microscopic examinations to confirm the presence and/or formation of exopolysaccharides during the selected growth stages. Yet, crystal violet assay has been used as a standard for early stages biofilm formation evaluation [47].
Thus, our results might have implications for designing further studies require certain levels of biofilm material at a specific stage of growth in a specific medium, and to investigate more about the molecular basis governed biofilm formation process under those specific parameters. As this study could be considered to highlight the effect of certain selected parameters on produced biofilm quantity from both antibiotic-resistant strains of $E$. coli and $K$. pneumoniae.

Our recommendation for further studies is to detect the level of resistance for each strain and relate it to biofilm formation amount.

\section{Conclusion}

This study demonstrated that the incubations conditions (static and shaking) and type of growth media are all critical factors influenced and regulated the amount of bacterial biofilm production in these selected ESBLs. In addition, different growth media also influenced the amount of biofilm formed by these pathogens. The diversity of biofilm formation response to different parameters suggested that Escherichia coli (CTX-M-15, TEM-3, and IMP-type) and Klebsiella pneumoniae (OXA-48, SHV-18, NDM-1, and KPC-3) strains have the potential to form the biofilms and the ability of individual ESBL strains to form biofilm and gradually to cause disease influenced by host factors and environmental conditions of the site of infection. Further investigation requires in biofilm quantification at a specific stage of growth in a specific medium, and to investigate more about the regulation of gene associated with biofilm formation and to detect the level of resistance for each strain in selected parameters.

\section{Acknowledgements}

The author wishes to thank The Higher Committee for Education Development in Iraq (HCED) for sponsoring and support my work.

\section{Author Contribution}

Conceived and Designed the Experiments: Baho $S$ and Samarasinghe S. Performed the Experiments: Baho. S. Analyzed data: Baho. S and Samarasinghe S. Wrote and Edited the paper: Baho S., Reid R. and Samarasinghe S.

\section{Conflict of Interest}

The authors declared that there is no conflict of interest.

\section{References}

1. Byarugaba DK (2005) Antimicrobial resistance and its containment in developing countries. Antibiotic Policies Springer, Boston, MA 617-647.

2. Walsh C (2000) Molecular mechanisms that confer antibacterial drug resistance. Nature 406: 775-781.

3. Centers for Disease Control and Prevention (2013) Modified Hodge test for carbapenemase detection in Enterobacteriaceae.

4. Paterson DL, Bonomo RA (2005) Extended-spectrum $\beta$-lactamases: a clinical update. Clin Microbiol Rev 18: 657-686.

5. Knothe H, Shah P, Krcmery V, Antal M, Mitsuhashi S (1983) Transferable resistance to cefotaxime, cefoxitin, cefamandole and cefuroxime in clinical isolates of Klebsiella pneumoniae and Serratia marcescens. Infection 11: 315-317.

6. Brun-Buisson C, Philippon A, Ansquer M, Legrand P, Montravers F, et al. (1987) Transferable enzymatic resistance to third-generation cephalosporins during nosocomial outbreak of multiresistant Klebsiella pneumoniae. Lancet 330: 302-306. 
7. Sirot D, Sirot J, Labia R, Morand A, Courvalin P, et al. (1987) Transferable resistance to third-generation cephalosporins in clinical isolates of Klebsiella pneumoniae: identification of CTX-1, a novel $\beta$-lactamase. J Antimicrob Chemother 20: 323-334.

8. Meletis G (2016) Carbapenem resistance: overview of the problem and future perspectives. Ther Adv Infect Dis 3: 15-21.

9. Walsh TR (2010) Emerging carbapenemases: a global perspective. Int J Antimicrob Agents 36: 8-14.

10. Poirel L, Pitout JD, Nordmann P (2007) Carbapenemases: molecular diversity and clinical consequences. Future Microbiol 2: 501-512.

11. Poirel L, Potron A, Nordmann P (2012) OXA-48-like carbapenemases: the phantom menace. J Antimicrob Chemother 67: 1597-1606.

12. Bjarnsholt $\mathrm{T}$ (2013) The role of bacterial biofilms in chronic infections. Apmis 121: 1-58.

13. Prigent-Combaret C, Vidal O, Dorel C, Lejeune P (1999) Abiotic surface sensing and biofilm-dependent regulation of gene expression in Escherichia coli. J Bacteriol 181: 5993-6002.

14. Parsek MR, Greenberg EP (2005) Sociomicrobiology: the connections between quorum sensing and biofilms. Trends Microbiol 13: 27-33.

15. Xu KD, Stewart PS, Xia F, Huang CT, Mc Feters GA (1998) Spatial physiological heterogeneity in Pseudomonas aeruginosa biofilm is determined by oxygen availability. Appl Environ Microbiol 64: 4035-4039.

16. Mikkelsen H, Duck Z, Lilley KS, Welch M (2007) Interrelationships between colonies, biofilms, and planktonic cells of Pseudomonas aeruginosa. J Bacteriol 189: 2411-2416.

17. Stewart PS, Costerton JW (2001) Antibiotic resistance of bacteria in biofilms. Lancet 358: 135-138.

18. Lewis HA, Furlong EB, Laubert B, Eroshkina GA, Batiyenko Y, et al. (2001) A structural genomics approach to the study of quorum sensing: crystal structures of three LuxS orthologs. Structure 9: 527-537.

19. Hall-Stoodley L, Costerton JW, Stoodley P (2004) Bacterial biofilms: from the natural environment to infectious diseases. Nat Rev Microbiol 2: 95.

20. Costerton JW, Stewart PS, Greenberg EP (1999) Bacterial biofilms: a common cause of persistent infections. Science 284: 1318-1322.

21. Parsek MR, Singh PK (2003) Bacterial biofilms: an emerging link to disease pathogenesis. Annu Rev Microbiol 57: 677-701.

22. Soto SM (2014) Importance of biofilms in urinary tract infections: new therapeutic approaches. Adv Biol 2014.

23. Anderson GG, Dodson KW, Hooton TM, Hultgren SJ (2004) Intracellular bacterial communities of uropathogenic Escherichia coli in urinary tract pathogenesis. Trends Microbiol 12: 424-430.

24. Stoodley P, Sauer K, Davies DG, Costerton JW (2002) Biofilms as complex differentiated communities. Annu Rev Microbiol 56: 187-209.

25. Stewart PS, Franklin MJ (2008) Physiological heterogeneity in biofilms. Nat Rev Microbiol 6: 199-210.

26. Becraft ED, Cohan FM, Kuhl M, Jensen SI, Ward DM (2011) Fine-scale distribution patterns of Synechococcus ecological diversity in microbial mats of Mushroom Spring, Yellowstone National Park. Appl Environ Microbiol 77: 7689-7697.

27. Kim W, Racimo F, Schluter J, Levy SB, Foster KR (2014) Importance of positioning for microbial evolution. Proc Natl Acad Sci USA 111: 1639-1647.

28. Ramsing NB, Ferris MJ, Ward DM (2000) Highly ordered vertical structure of Synechococcus populations within the one-millimeter-thick photic zone of a hot spring cyanobacterial mat. Appl Environ Microbiol 66: 1038-1049.

29. Rani SA, Pitts B, Beyenal H, Veluchamy RA, Lewandowski Z, et al. (2007) Spatial patterns of DNA replication, protein synthesis, and oxygen concentration within bacterial biofilms reveal diverse physiological states. J Bacteriol 189: 4223-4233.

30. Rasmussen K, Lewandowski Z (1998) Microelectrode measurements of local mass transport rates in heterogeneous biofilms. Biotechnol Bioeng 59: 302-309.
31. Werner E, Roe F, Bugnicourt A, Franklin MJ, Heydorn A, et al. (2004) Stratified growth in Pseudomonas aeruginosa biofilms. Appl Environ Microbiol 70: 6188-6196

32. Boles BR, Thoendel M, Singh PK (2004) Self-generated diversity produces insurance effects in biofilm communities. Proc Natl Acad Sci USA 101: $16630-16635$.

33. Hansen SK, Rainey PB, Haagensen JA, Molin S (2007) Evolution of species interactions in a biofilm community. Nature 445: 533.

34. Baty AM, Eastburn CC, Diwu Z, Techkarnjanaruk S, Goodman AE, et al. (2000) Differentiation of chitinase-active and non-chitinase-active subpopulations of a marine bacterium during chitin degradation. Appl Environ Microbiol 66: 3566-3573.

35. Baty AM, Eastburn CC, Techkarnjanaruk S, Goodman AE, Geesey GG (2000) Spatial and temporal variations in chitinolytic gene expression and bacterial biomass production during chitin degradation. Appl Environ Microbiol 66: 3574-3585.

36. Vlamakis H, Aguilar C, Losick R, Kolter R (2008) Control of cell fate by the formation of an architecturally complex bacterial community. Genes Dev 22: 945-953.

37. Gelens L, Hill L, Vandervelde A, Danckaert J, Loris R (2013) A general model for toxin-antitoxin module dynamics can explain persister cell formation in E. coli. PLoS Comput Biol 9: 1003190.

38. Mast G (2015) ESBL and AmpC detection disc sets. Bootle: Mast House.

39. BSAC (2015) BSAC methods for antimicrobial susceptibility testing. BSAC (ed.)

40. Garrec H, Drieux-Rouzet L, Golmard JL, Jarlier V, Robert J (2011) Comparison of nine phenotypic methods for detection of extendedspectrum $\beta$-lactamase production by Enterobacteriaceae. J Clin Microbiol 49: $1048-1057$.

41. Beehan DP, Wolfsdorf K, Elam J, Krekeler N, Paccamonti D, et al. (2015) The evaluation of biofilm-forming potential of Escherichia coli collected from the equine female reproductive tract. J Equine Vet Sci 35: 935-939.

42. Lee JH, Regmi SC, Kim JA, Cho MH, Yun H, et al. (2011) Apple flavonoid phloretin inhibits Escherichia coli O157: H7 biofilm formation and ameliorates colon inflammation in rats. Infect Immun 79: 4819-4827.

43. Fattahi S, Kafil HS, Nahai MR, Asgharzadeh M, Nori R, et al. (2015) Relationship of biofilm formation and different virulence genes in uropathogenic Escherichia coli isolates from Northwest Iran. GMS Hyg Infect Control 10.

44. Atshan SS, Shamsudin MN, Karunanidhi A, van Belkum A, Lung LTT, et al. (2013) Quantitative PCR analysis of genes expressed during biofilm development of methicillin resistant Staphylococcus aureus (MRSA). Infect Genet Evol 18: 106-112.

45. Rabin N, Zheng Y, Opoku-Temeng C, Du Y, Bonsu E, et al. (2015) Biofilm formation mechanisms and targets for developing antibiofilm agents. Future Med Chem 7: 493-512.

46. Stepanovic S, Cirkovic I, Ranin L (2004) Biofilm formation by Salmonella spp. and Listeria monocytogenes on plastic surface. Lett Appl Microbiol 38: 428-432.

47. Reisner A, Krogfelt KA, Klein BM, Zechner EL, Molin S (2006) In vitro biofilm formation of commensal and pathogenic Escherichia coli strains: impact of environmental and genetic factors. J Bacteriol 188: 3572-3581.

48. Cremet L, Corvec S, Batard E, Auger M, Lopez I, et al. (2013) Comparison of three methods to study biofilm formation by clinical strains of Escherichia coli. Diagn Microbiol Infect Dis 75: 252-255.

49. O'Toole GA (2011) Microtiter dish biofilm formation assay. J Vis Exp 47.

50. Justice SS, Hung C, Theriot JA, Fletcher DA, Anderson GG, et al. (2004) Differentiation and developmental pathways of uropathogenic Escherichia coli in urinary tract pathogenesis. Proc Natl Acad Sci USA 101: 1333-1338.

51. Anderson GG, Palermo JJ, Schilling JD, Roth R, Heuser J, et al. (2003) Intracellular bacterial biofilm-like pods in urinary tract infections. Science 301: 105-107. 
Citation: Baho S, Reid R, Samarasinghe S (2018) Adaptability to Various Growth Conditions of Biofilm Associated Extended-Spectrum-BetaLactamases Producing Bacteria. J Infect Dis Diagn 3: 121. doi:10.4172/2576-389X.1000121

Page 9 of 9

52. Fux CA, Shirtliff M, Stoodley P, Costerton JW (2005) Can laboratory reference strains mirror real-worldpathogenesis? Trends Microbiol 13: $58-63$.
53. Corehtash ZG, Ahmad Khorshidi FF, Akbari H, Aznaveh AM (2015) Biofilm formation and virulence factors among Pseudomonas aeruginosa isolated from burn patients. Jundishapur J Microbiol 8. 